\title{
Learning experience facilitates sparse coding of new odors in a large-scale olfactory bulb model
}

Shanglin Zhou ${ }^{1 *}$, Boqiang Fan ${ }^{1}$, Michele Migliore², Yuguo Yu ${ }^{1 *}$

From 24th Annual Computational Neuroscience Meeting: CNS*2015

Prague, Czech Republic. 18-23 July 2015

Odor responses of mitral cells in the olfactory bulb are observed to be sparse spatially and decorrelated in response to odor signals [1]. We have built a large scale biophysical network model of olfactory bulb composed of mitral and granule cells, corresponding to 1/100th of the real system in the rat, and used direct experimental imaging data of glomeruli activated by various odors. Our previous reports have showed that a sparse spatial

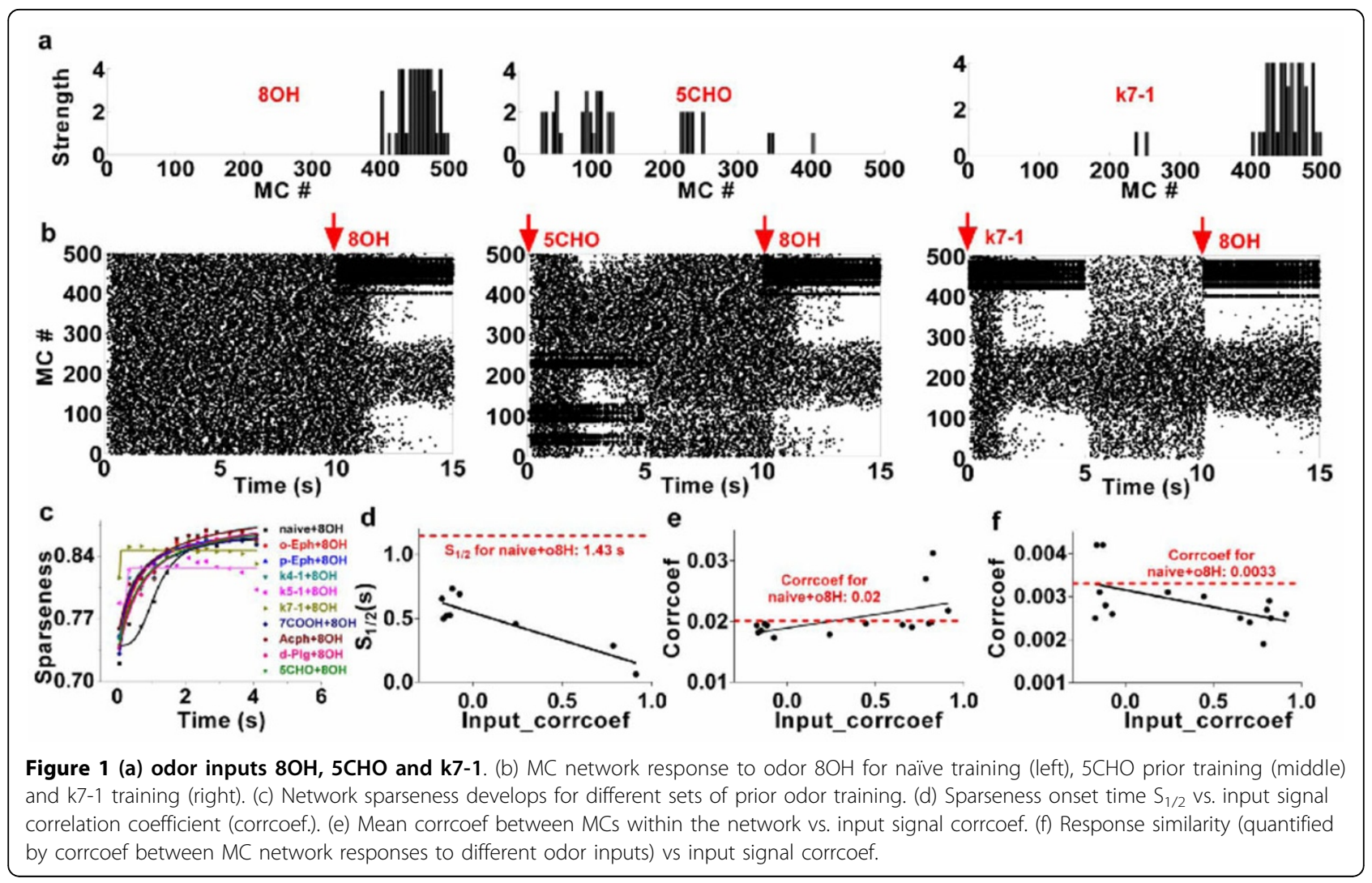

\footnotetext{
* Correspondence: yuyuguo@fudan.edu.cn

${ }^{1}$ School of Life Sciences, the State Key Laboratory of Medical Neurobiology and Institutes of Brain Science, Fudan University, Shanghai, 200433, China Full list of author information is available at the end of the article
} 
spiking representation of specific odor signals can emerge naturally within several seconds learning period from the mitral-granule cell interactions, realistically implemented in our model with self-organizing dendrodendritic synapses driven by mitral cell activity [2]. To address how the prior odor experience interfere with subsequent sparse coding of new coming odors, we trained the network with a set of odors (Figure 1a and 1b, note that no signal in left panel of Figure $1 \mathrm{~b}$ which is called native state) to reach a stable response state (sniff frequency around 4-10 Hz) within 5 seconds (Figure 1a), and then a second odor (e.g., octanol $8 \mathrm{OH}$ ) was input to the network (5s, 4-10 Hz) (Figure 1b, middle and right). Compared to the network trained from the native state (Figure 1b, left), prior active odor training could significantly facilitate the whole mitral cell network into different degrees of response sparseness for odor $8 \mathrm{OH}$ (see right two panels in Figure 1b). The sparseness onset time S1/2 (defined as the time reached the half of maximum sparseness) is relatively large for input signals with less similarity (Figure 1c) while become shorter as more input similarity is induced (Figure 1d, correlation coefficient $r=0.89$ ), however, all shorter than that in native situation (Figure 1c, d), suggesting prior training experience could significantly promote odor perception of even novel odors.

Furthermore, for the most of total 16 prior odor training tests, the mean correlation coefficients between MT cells within the network measured at the end of afterlearning process (i.e. No.14-15s) are less than the native situation (Figure 1e), suggesting a more decorrelated state. Correspondingly, the similarity of the MT network responses for most of the tests is lower significantly than the naïve case (Figure 1f). This strongly suggests prior odor experience could significantly promote odor discrimination ability of the olfactory bulb network. In sum, odor experience could accelerate the formation of network response sparseness, decorrelation, and promote signal discrimination.

\section{Acknowledgements}

This project is funded by NNSF of China (31271170) and Shanghai Eastern Scholar program SHH1140004).

\section{Authors' details}

'School of Life Sciences, the State Key Laboratory of Medical Neurobiology and Institutes of Brain Science, Fudan University, Shanghai, 200433, China.

${ }^{2}$ Institute of Biophysics, National Research Council, 90146 Palermo, Italy.

Published: 18 December 2015

\section{References}

1. Kato Hiroyuki K, Chu Monica W, Isaacson Jeffry S, Komiyama T: Dynamic Sensory Representations in the Olfactory Bulb: Modulation by Wakefulness and Experience. Neuron 2012, 76(5):962-975.

2. Yu Y, Migliore M, Hines ML, Shepherd GM: Sparse coding and lateral inhibition arising from balanced and unbalanced dendrodendritic excitation and inhibition. J Neurosci 2014, 34(41):13701-13713.
doi:10.1186/1471-2202-16-S1-P297

Cite this article as: Zhou et al:: Learning experience facilitates sparse coding of new odors in a large-scale olfactory bulb model. BMC

Neuroscience 2015 16(Suppl 1):P297.

\section{Submit your next manuscript to BioMed Central and take full advantage of:}

- Convenient online submission

- Thorough peer review

- No space constraints or color figure charges

- Immediate publication on acceptance

- Inclusion in PubMed, CAS, Scopus and Google Scholar

- Research which is freely available for redistribution

Submit your manuscript at www.biomedcentral.com/submit
C Biomed Central 